\title{
Simulasi Manajemen Bencana Dapat Meningkatkan Pengetahuan dan Skill Mahasiswa Keperawatan: Literature Review
}

\author{
Putu Juni Andika ${ }^{1}$, Sri Sundari ${ }^{2}$ \\ ${ }^{1}$ Mahasiswa Magister Keperawatan, Universitas Muhammdiyah Yogyakarta \\ ${ }^{2}$ Fakultas Kedokteran dan IImu Kesehatan, Universitas Muhammadiyah Yogyakarta \\ Correspondence email: putujuniandikadtd13@gmail.com
}

\begin{abstract}
Indonesia has a very high level of disaster vulnerability. Earthquake disasters can occur at any time without being predicted. It is important to implement disaster management simulations in nursing learning to improve the knowledge and skills of nursing students. This paper purpose to find out whether disaster simulation can improve the knowledge and skills of nursing students. This literature uses inclusion and exclusion criteria, articles obtained and reviewed from databases namely Google Scholar (2008 - 2018) and PubMed (2008 - 2018). The search strategy and terminology used in English is as follows: simulation OR disaster or earthquake OR knowledge OR nursing student. Ten articles were obtained from search results. Eight articles mention earthquake disaster simulations significantly increasing student knowledge and skills. While the two articles stated that disaster management simulation does not increase knowledge but increases attitudes or familiarity in the team and satisfaction. Disaster simulation is one of the methods and strategies in a learning system that has a positive impact, especially in the field of nursing education, especially in response to earthquake management?
\end{abstract}

Keywords: Simulation, disaster earthquake, knowledge, skills, nursing, literature review

\section{PENDAHULUAN}

Metode yang digunakan dalam pembelajaran simulasi manajemen bencan gempa bumi, bertujuan untuk meningkatkan pengetahuan dan skill, Perawat memiliki peranan penting dalam mempersiapkan manajemen bencana gempa bumi yang profesional untuk mengurangi morbiditas dan mortalitas. Kesiapan terhadap bencana, termasuk penilaian tingkat resiko dan strategi manajemen multi-disiplin disemua tingkatan sistem untuk penyampian respon yang efektif terhadap kebutuhan jangka panjang, menengah dan pendek dari populasi yang dilanda bencana (Yan et al., 2015).

Tujuan pembelajaran simulasi manajemen bencana gempa bumi adalah untuk meningkatkan pengetahuan dan skill, desain simulasi efektif untuk praktik belajar mahasiswa keperawatan. Sebagaian besar mahasiswa memerlukan banyak waktu untuk memahami manajeman bencana (Xia et al., 2016). Simulasi sebagai strategi pengajaran yang terbukti dan merupakan pendekatan yang efektif untuk meningkatkan kerja tim dan pembelajaran aktif.

Menurut Widodo (2015:82), pelatihan merupakan serangkaian aktivitas individu dalam meningkatkan keahlian dan pengetahuan secara sistematis sehingga mampu memiliki kinerja yang profesional di bidangnya. Pelatihan adalah proses pembelajaran yang memungkinkan pegawai melaksanakan pekerjaan yang sekarang sesuai dengan standar.

Simulasi Disaster Management adalah suatu proses atau strategi yang diterapkan sebelum, selama atau setelah jenis peristiwa bencana terjadi. Proses ini dilakukan ketika sesuatu mengancam, mengganggu atau menempatkan kehidupan masyarakat yang dapat beresiko dalam bencana alam. Merancanakan dan membangun rumah sakit yang tahan gempa, mengadopsi program dan kebijakan nasional dalam melindungi peralatan, bahan, dan persediaan medis. Selama dan setelah bencana gempa bumi terjadi, rumah sakit dianggap sebagai lingkungan teraman bagi orangorang dalam terjadi bencana, karena mereka memberikan perawatan vital bagi para korban gempa bumi (Abdelghany Ibrahim, 2014).

Dari paparan fenomena kasus yang ada, apakah simulation disaster eartquake mampu meningkatkaan pengetahuan dan skill mahasiswa keperawatan dalam kesiapsiagaan merespon bencana gempa bumi ? Untuk menjawab pertayaan ini, penulis melakukan tinjauan literature review dalam publikasi yang relavan sesuai topik yang dibahas.

\section{METODE PENELITIAN Tujuan}

Paper ini bertujuan untuk mengetahui apakah metode simulasi disaster earthquake dapat meningkatkan pengetahuan dan skill mahasiswa keperawatan?

\section{Kriteria inklusi dan eksklusi}

Kriteria inklusi berikut ini digunakan dalam pemilihan literatur riview ini:

- Penelitian yang orisinil ( jurnal asli atau memang dilakukan oleh peneliti)

- Full text.

- Penelitian berkaitan dengan simulation disaster earthquake knwolegde dan skills student nursing

- mengatakan berpengaruh terhadap peningkatan pengetahuan dan skill

- Jurnal dimulai dari tahun 2008 sampai 2018

- Artikel/jurnal tersedia dalam bahasa Indonesia dan bahasa Inggris

Kriteria ekslusi berikut digunakan dalam pemilihan studi untuk literature ini:

- Publikasi tidak asli seperti, surat ke editor, abtrak saja, dan editoral.

\section{Sumber Data dan Pencarian}

Pencarian artikel ini dilakukan dengan menggunakan internet data base melalui google scholar (2008-2018) dan pubMed (2008-2018) pada bulan desember 2018. Tidak ada batasan pada tanggal 
publikasi disetiap database. Strategi pencarian yang dilakukan menggunakan kata kunci dalam bahasa inggris: "simulation $O R$ disaster $O R$ earthquake $O R$ knowledge OR nursing students.

Hal ini agar memastikan semua artikel yang diperoleh relevan dan sesuai, selanjutnya full text di unduh dan disimpan.

\section{penyeleksian}

Setelah idendefikasi awal judul dan abstrak, pada google scholar di peroleh 6.000, pada PubMed diperoleh 32.000 artikel, jadi total keseluruhan diperoleh 38.000 artkel. Penelitian diskrining melalui judul dan abstrak kemudian diperoleh 752 artikel. Peneliti melakukan review dengan kategori full text sehingga diperoleh 553 artikel yang tersisa dan diperiksa secara independen, sesuai kriteria inklusi sehingga mernjadi 199, artikel dieksklusi karena tidak memenuhi kriteria dengan jumlah 189 artikel. Artikel selanjutya dalam tahap akhir diperoleh 10 artikel.

\section{HASIL DAN PEMBAHASAN}

Fokus utama dalam literature review ini adalah management disaster sumulation untuk meningkatkan pengetahuan dan skill mahasiswa. Untuk mengoptimalkan interpretasi ini, pertama-tama kita akan mengklarifikasi hasil temuan. Alur pencarian dirangkum pada gambar table.

Tabel 1. Proses Pencarian Artikel

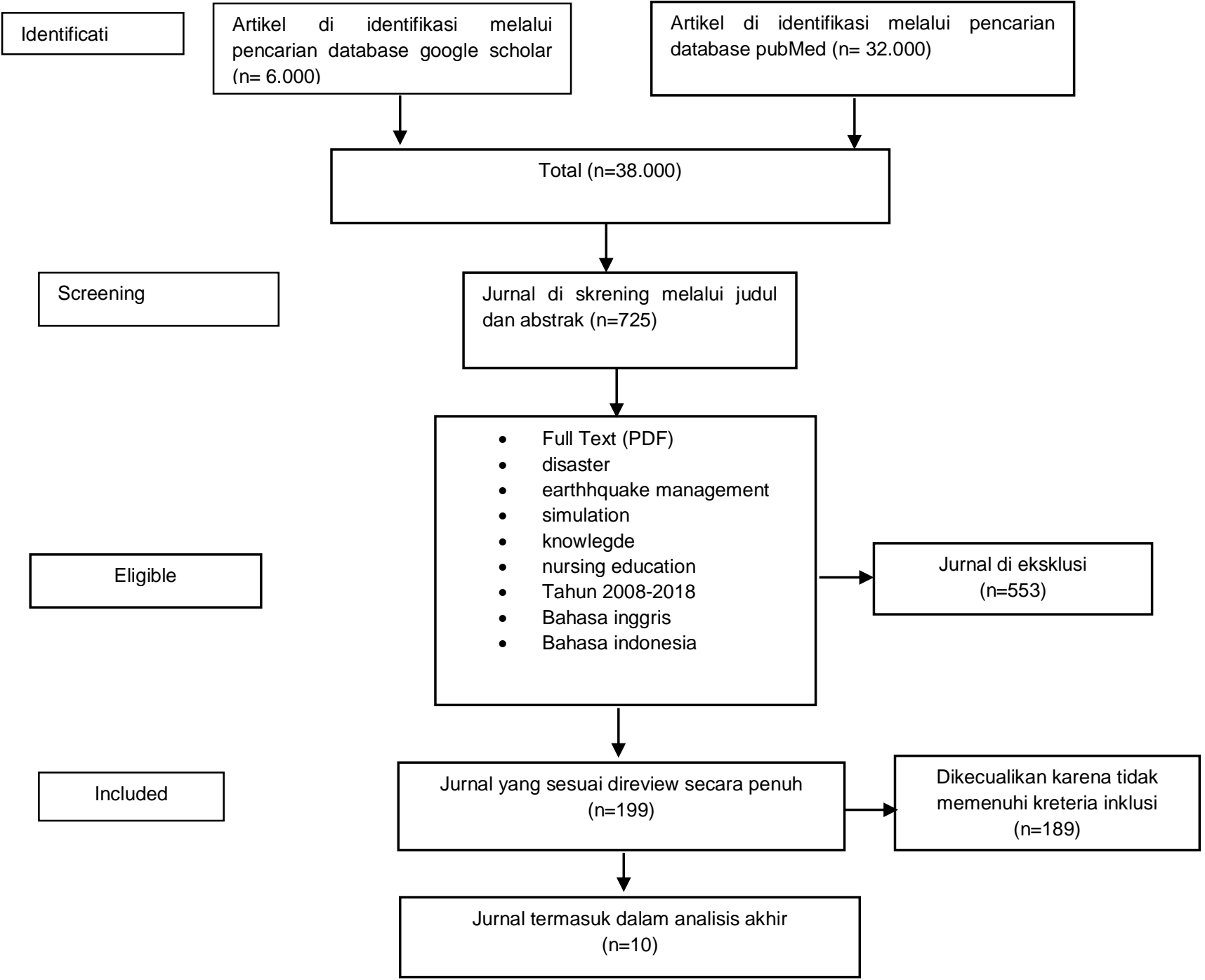

Tabel 2. Studi Karakteristik

\begin{tabular}{|c|c|c|c|c|c|c|}
\hline No & Author & Title & $\begin{array}{c}\text { Method } \\
\text { study/Study } \\
\text { design }\end{array}$ & Tujuan & Sample & Outcome \\
\hline 1 & $\begin{array}{l}\text { (Unver et al., } \\
\text { 2018) }\end{array}$ & $\begin{array}{l}\text { Analysis of the effects } \\
\text { of high-fidelity } \\
\text { simulation on nursing } \\
\text { students' perceptions of } \\
\text { their preparedness for } \\
\text { disasters }\end{array}$ & $\begin{array}{l}\text { Quasi- } \\
\text { experimental }\end{array}$ & $\begin{array}{l}\text { Pre-test and pos- } \\
\text { test, tools } \\
\text { sosiodemografi }\end{array}$ & $\begin{array}{l}87 \text { mahasiswa } \\
\text { keperawatan } \\
\text { senior }\end{array}$ & $\begin{array}{l}\text { Mendukung kegiatan simulasi } \\
\text { dengan latihan berdampak positif } \\
\text { terhadap persepsi perawat } \\
\text { tentang bencana }\end{array}$ \\
\hline 2 & $\begin{array}{l}\text { (Farhadloo et } \\
\text { al., 2018) }\end{array}$ & $\begin{array}{l}\text { Investigating the Effect } \\
\text { of Training With the } \\
\text { Method of Simulation }\end{array}$ & $\begin{array}{l}\text { Quasi- } \\
\text { experimental }\end{array}$ & $\begin{array}{l}\text { Evaluasi } \\
\text { Quesioner }\end{array}$ & 70 siswa & $\begin{array}{l}\text { Simulasi bencana triase secara } \\
\text { signifikan meningkatkan } \\
\text { pengetahuan siswa }\end{array}$ \\
\hline
\end{tabular}


on the Knowledge and Performance of Nursing Students in the PreHospital Triage

3 (Nofal et al., Knowledge, attitudes, n.d., 2018) and practices of emergency department staff towards disaster and emergency preparedness at tertiary health care hospital in central Saudi Arabia

4 (Foronda et Impact of Virtual al., 2016) Simulation to Teach Concepts of Disaster Triage n.d., Empathy through Real-Time ProblemBased Simulations: Outcomes from a Policymaking

Simulation set in PostEarthquake Haiti

6 (Yan et al., Disaster nursing skills, 2015) knowledge and attitudes required in earthquake relief: implications for nursing education

(Abdelghany Nurses knowledge, Ibrahim, attitudes, practices and 2014) familiarity regarding disaster and emergency preparedness -

Saudi Arabia

8 (Sangkala

Disaster preparedness and Gerdtz, and learning needs 2018) among community healthnurse coordinators in South Sulawesi Indonesia

9 (Farra et al., Improved Training for 2013) Disasters Using 3-D Virtual Reality Simulatio

10 (Xia et al., Application and effects 2016) of a disaster nursing simulation training for Chinese undergraduates

\section{Cross-sectional Survei and review 189 peserta}

Mixed-method

pretest / post-test 7 siswa

pretest / posttest Tidak dan focus group disebutkan dalam penelitian

Mixed method

Survey quesioner

139 perawat

Mixed method

Pre-test dan posttest

225

responden

$\begin{array}{ccll}\text { cross-sectional } & \begin{array}{c}\text { Survei } \\ \text { evaluation }\end{array} & \text { and } & 425 \\ & \text { responden }\end{array}$

longitudinal experimental

Qualitative

Control group 40 siswa keperawatan

Implementasi and 120 siswa evaluasi
Tingkat pengetahuannya sangat memuaskan di antara penyedia layanan kesehatan dengan tingkat sikap netral, praktek, dan pengetahuan tentang kesiapsiagaan bencana.

simulasi virtual dapat menjadi solusi pengajaran untk meningkatkan pengetahuan dan skill mahasisa dalam menghadapi bencana

simulasi disaster manajeman dapat menjadi alat simulasi mengukur empati masyarakat dan siswa meningkat dalam isuisu gempa bumi secara signifikan,

mahasiswa keperawatan masih kurang siap untuk perawatan bencana di Cina dan juga menyadari apa yang akan berguna di lokasi bencana, namun proses pembelajaran menjadi menarik

tingkat pengetahuan dan praktik sangat kurang $d$ bandingkan dengan tingkat sikap yang signifikan mengena kesiapsiagaan bencana .

peserta menganggap latihan bencana yang sering sebagai metode pembelajaran terbaik untuk mencapai kesiapsiagaan bencana yang efektif.

Efek simulasi virtual sangat signifikan dalam meningkatkan penetahuan dan skillt

bahwa desain simulasi efektif dan mempromosikan praktik belajar siswa. Skala Kepuasan dan Percaya Diri

menunjukkan kepuasan dengan pembelajaran saat ini dan kepercayaan diri dalam belajar

\section{Karakteristik Metodelogi}

Dari 10 artikel yang ditinjau, empat orang artikel menggunakan studi desain mixed method (Foronda et al., 2016: Raymond et al., n.d.,2016; Yan et al., 2015; Abdelghany Ibrahim, 2014), dua artikel menggunakan Quasi-experimental (Unver et al., 2018; Farhadloo et al., 2018), dua artikel menggunakan cross-sectional (Nofal et al., n.d., 2018: Sangkala and Gerdtz, 2018), satu artikel menggunakan logitudinal experimental (Farra et al., 2013) dan satu artikel menggunakan Qualitative (Xia et al., 2016).

\section{Metode Intervensi}

Dari 10 artikel tersebut, lima artikel menggunakan proses rancangan dengan post-test untuk intervensi (Unver et al., 2018; Foronda et al., 2016; Abdelghany Ibrahim, 2014: Raymond et al., n.d., 2016), satu artikel menggunakaan evaluasi dan Quesioner (Farhadloo et al., 2018), satu artikel menggunakan survei and interview (Nofal et al., n.d., 2018), satu penelitian menggunakan surve quesioner (Yan et al., 2015), satu artikel menggunakan surve and evaluation (Sangkala and Gerdtz, 2018), satu artikel menggunakan control group (Farra et al., 2013), dan satu artikel menggunakan implementasi dan evaluation (Xia et al., 2016).

\section{Hasil}

Dari 10 artikel yang direview secara penuh, delapan artikel menyebutkan simulasi bencana secara signifikan meningkatkan penegtahuan dan efektif digunakan (Farhadloo et al., 2018; Nofal et al., n.d., 2018; Raymond et al., n.d., 2016; Sangkala and Gerdtz, 2018; Farra et al., 2013; Xia et al., 2016; Unver et al., 2018; Foronda et al., 2016), dua artikel menyebutkan pemberian simulasi menunjukkan sikap dengan hasil 
yang memuaskan (Abdelghany Ibrahim, 2014; Yan et al., 2015).

\section{Diskusi}

Secara total literatur rieview diperoleh sepuluh. Delapan artikel tersebut menyebutkan hasil yang signifikan antara lain: Simulasi bencana dalam triase secara signifikan meningkatkan pengetahuan mahasiswa keprawatan (Farhadloo et al., 2018), tingkat pengetahuanny sangat memuaskan di antara penyedia layanan kesehatan seperti perawat dengan sikap, praktik, dan keakraban netral terkait kesiapan bencana. (Nofal et al.,n.d., 2018), simulasi disaster manajeman dapat menjadi alat simulasi untuk mendorong kesadaran masyarakat dan mahasiswa akan isu-isu bencana gempa bumi dalam masyarakat (Raymond et al., n.d., 2016), simulasi manajemen bencana sebagai strategi metode pembelajaran yang baik untuk mencapai kesiap siaga yang efektif (Sangkala and Gerdtz, 2018), VRS (virtual Reality Simulation) adalah metode pembelajaran yang memperkuat sistem pembelajaran dan meningkatkan retensi belajar mahasiswa (Farra et al., 2013), Simulasi sebagai strategi pembelajaran yang efektif untuk meningkatkan kerja tim, pembelajaran aktif, penyelesaian masalah, tingkat kepuasan dan kepercayaan diri selama pelatihan simulasi bencana gempa bumi pada mahasiswa keperawatan (Xia et al., 2016), Kegiatan pembelajaran simulasi akan berdampak positif terhadap persepsi mahasiswa keperawatan tentang manajeman bencana (Unver et al., 2018), pembelajaran simulasi virtual dapat menjadi solusi untuk meningkatkan pengetahuan dan skill mahasisa keperawatan dalam menghadapi bencana gempa bumi (Foronda et al., 2016), dua artikel menyebutkan pendapat yang berbeda yaitu simulasi tidak meningkatkan pengetahuan namun ada peningkatan dalam aspeks lain: simulasi tidak ada peningkatan terhadap pengetahuan tetapi meningkatkan sikap yang signifikan mengenai kesiapsiagaan bencana (Abdelghany Ibrahim, 2014), simulasi tidak meningkatkan pengetahuan karena mahasiswa masih belum siap siaga dalam menghadapi bencana gempa bumi di Cina, serta belum memahami tindakan apa yang akan dilakukan di lokasi bencana gempa bumi, (Yan et al., 2015). Meskipun ada beberapa artikel yang menunjukkan hasil yang signifikan terkait simulasi manajemen bencana gempa bumi terhadap peningkatan pengetahuan dan skill mahasiswa keperawatan. Sepuluh artikel memiliki kelebihan dan kekurangan sesuai metodologi penelitian yang digunakan seperti yang ada diatas. Dalam sepuluh artikel memiliki studi design, sample dan intervensi pembelajaran terkait simulasi yang bervariasi dalam setiap artikel. Artikel menggunakan Studi design yang beragam, empat artikel menggunakan desain mixed method (Foronda et al., 2016: Raymond et al., n.d., 2016; Yan et al., 2015; Abdelghany Ibrahim, 2014). Misalnya dalam pembelajaran simulasi bencana gempa bumi menggunakan metode simulasi 3D-viartual reality kepada responden (Farra et al., 2013), sedangkan artikel yang lain menggunakan sosiodemografi untuk mengetahui pandangan mereka tentang kesiapan dalam menghadapi bencana gempa bumi dan skala persepsi
(Unver et al., 2018), dan artikel yang lain menggunakan metode tes triasse untuk memeriksa kinerja triase yang sesuai bedasarkan tingkat keparahan pada korban bencana gempa bumi (Farhadloo et al., 2018a).

Farhadloo et al.,(2018), pelatihan dengan metode simulasi pada model pembelajran sangat efektif pada kesiapsiagaan profesi perawat untuk melakukan triase ketika terjadi kecelakaan dan keadaan darurat pada saat terjadi bencana gempa bumi. Ditemukan juga bahwa pelatihan simulasi manajemen gempa bumi dapat meningkatkan pengetahuan dan skill mahasiswa dalam kesiapsiagaan mereka untuk menghadapi bencana gempa bumi. Salah satu kekuatan simulasi bencana adalah bagian dari kurikulum pendidikan keperawatan dan pelatihan kerja yang bisa menjadi solusi yang baik untuk kesiap siaga bencana dalam meningkatkan pengetahuan dan skill mahasiswa keprawatan (Sangkala and Gerdtz, 2018), meskipun sebagian mahasiswa mengatakan mereka siap untuk menghadapi bencana gempa bumi, dalam kegiatan simulasi manajemen gempa bumi dapat mengasilkan dampak yang positif untuk mempersiapkan persepsi mahasiswa keperawatan tentang bencana. Salah satu kelemahan metode simulasi bencana gempa bumi adalah masalah teknis yang yang perlu diperbaiki guna menunjang fleksibilitas pembelajaran simulasi bencana sebelum penerapan lebih lanjut.

Simulasi disaster manajemen bencana dalam penelitian menyebutkan bisa juga menggunakan rancangan 3D-virtual reality simulator, sehingga mahasiswa bener-bener merasakan suasana seperti gempa bumi yang sesungguhnya (Farra et al., 2013). Sebagai tambahan pendidik keperawatan, manajemen bencana dan pembuat kebijakan untuk mengidentifikasi persepsi mereka dalam hal bencana gempa bumi yang efektivitas dalam pembelajaran simulasi manajemen bencana untuk mengeksplorasi kebutuhan pembelajaran manajemen bencana pada umumnya (Sangkala and Gerdtz, 2018)

Simulasi manajemen bencana gempa bumi adalah salah satu metode Simulasi strategi pembelaran dengan pendekatan yang sangat efektif untuk meningkatkan kerja tim, pembelajaran aktif, penyelesaian masalah, tingkat kepuasan dan kepercayaan diri selama pelatihan keperawatan manajeman bencana. Perawat pendidik harus menyediakan program pelatihan simulasi bencana untuk sarjana keperawatan dalam mempersiapkan mereka untuk berperan aktif dalam merespon bencana gempa bumi (Xia et al., 2016). Pengetahuan yang meningkat karena terjadi proses metode dalam pembelajaran simulasi yang sangat efektif dan tidak menoton sehingga bermanfaat dalam kesisapsiagaan menghadapi bencana (Farhadloo et al., 2018). Teori dan praktik dalam pembelajaran simulasi khususnya tentang manajemen bencana dan kesiapsiagaan darurat ke dalam kurikulum keperawatan sangat penting dan dibutuhkan, pelatihan simulasi manajemen bencana gempa bumi sebagai preferensi. Selanjutnya, diperlukan untuk memaksimalkan kualitas perawat dalam area kritis yang diterapkan pada layanan kesehatan keperawatan dan kesehatan masyarakat seperti perawatan komunitas (Abdelghany Ibrahim, 2014). Dengan demikian, sebuah 
penelitian tentang simulasi manejemen bencana gempa bumi Sangat penting bagi para pendidik keperawatan untuk meningkatkan pengetahuan dan skill serta menyediakan program keperawatan bencana bagi sarjana keperawatan dalam mempersiapkan mereka untuk berperan aktif dalam respons bencana gempa bumi (Xia et al., 2016)

\section{SIMPULAN}

Bedasarkan hasil literatur review di ketahui bahwa efektivitas yang ditunjukkan oleh metode pembelajaran simulasi disaster manajemen bencana gempa bumi sangat berpengaruh dalam meninkakan pengeatahuan dan skill mahasiswa keperawatan. Metode simulasi disaster manajemen bencana gemp[a bumi merupakan salah satu metode yang sangat membantu dalam mencapai hasil, dimana metode ini adalah salah satu pembelajaran yang memiliki kelebihan dalam praktek yang menarik dengan didukung oleh fasilias dan sarana prasarana seperti Virtual-3D. Simulasi disaster manajemen bencana gempa bumi memiliki ke kurangan yaitu informasi tentang bagaimana penanganan cedera kimia, biologis, radiologis dan nuklir untuk dapat dalam disediakan pembelajaran pembelajaran simulasi manajemen bencana, tetapi masalah ini tidak tercakup dalam kegiatan simulasi.

Analisis ini menunjukkan bahwa disaster manajemen mendukung dalam peningkatan pengetahuan skill mahasiswa keperawatan. Diharapkan institusi dapat mengembangkan metode simulasi manajemen bencana gempa bumi dalam proses belajar mengajar.

\section{DAFTAR PUSTAKA}

Abdelghany Ibrahim, F.A., 2014. Nurses Knowledge, Attitudes, Practices and Familiarity Regarding Disaster and Emergency Preparedness - Saudi Arabia. American Journal of Nursing Science 3, 18. https://doi.org/10.11648/j.ajns.20140302.12

Farhadloo, R., Department of Emergency Medicine, School of Medicine, Qom University of Medical Sciences, Qom, Iran., Kashani Nejad, M., Disaster and Emergency Medicine Management Center, Qom University of Medical Sciences, Qom, Iran., Haji Mohammad Hoseini, M., Department of Emergency Medicine, School of Medicine, Qom University of Medical Sciences, Qom, Iran., Vahedian, M., Clinical Research Development Center, Qom University of Medical Sciences, Qom, Iran., Parvaresh Masoud, M., Department of Emergency Medicine, School of Medicine, Qom University of Medical Sciences, Qom, Iran., 2018a. Investigating the Effect of Training With the Method of Simulation on the Knowledge and Performance of Nursing Students in the PreHospital Triage. Health in Emergencies and Disasters Quarterly 3, 123-130. https://doi.org/10.29252/nrip.hdq.3.3.123

Farhadloo, R., Department of Emergency Medicine, School of Medicine, Qom University of Medical Sciences, Qom, Iran., Kashani Nejad, M., Disaster and Emergency Medicine Management Center, Qom University of Medical Sciences, Qom, Iran.,
Haji Mohammad Hoseini, M., Department of Emergency Medicine, School of Medicine, Qom University of Medical Sciences, Qom, Iran., Vahedian, M., Clinical Research Development Center, Qom University of Medical Sciences, Qom, Iran., Parvaresh Masoud, M., Department of Emergency Medicine, School of Medicine, Qom University of Medical Sciences, Qom, Iran., 2018b. Investigating the Effect of Training With the Method of Simulation on the Knowledge and Performance of Nursing Students in the PreHospital Triage. Health in Emergencies and Disasters Quarterly 3, 123-130. https://doi.org/10.29252/nrip.hdq.3.3.123

Farra, S., Miller, E., Timm, N., Schafer, J., 2013. Improved Training for Disasters Using 3-D Virtual Reality Simulation. Western Journal of Nursing Research 35, 655-671. https://doi.org/10.1177/0193945912471735

Foronda, C.L., Shubeck, K., Swoboda, S.M., Hudson, K.W., Budhathoki, C., Sullivan, N., Hu, X., 2016. Impact of Virtual Simulation to Teach Concepts of Disaster Triage. Clinical Simulation in Nursing 12, 137-144. https://doi.org/10.1016/j.ecns.2016.02.004

Nofal, A., Alfayyad, I., Khan, A., Aseri, Z.A., AbuShaheen, A., n.d. Knowledge, attitudes, and practices of emergency department staff towards disaster and emergency preparedness at tertiary health care hospital in central Saudi Arabia 7.

Raymond, C., Zappile, T., Beers, D.J., n.d. Promoting Global Empathy and Engagement through RealTime Problem-Based Simulations: Outcomes from a Policymaking Simulation set in Post-Earthquake Haiti 40.

Sangkala, M.S., Gerdtz, M.F., 2018. Disaster preparedness and learning needs among community health nurse coordinators in South Sulawesi Indonesia. Australasian Emergency Care 21, 23-30. https://doi.org/10.1016/j.auec.2017.11.002

Unver, V., Basak, T., Tastan, S., Kok, G., Guvenc, G., Demirtas, A., Ayhan, H., Köse, G., lyigun, E., Tosune, N., 2018. Analysis of the effects of highfidelity simulation on nursing students' perceptions of their preparedness for disasters. International Emergency Nursing 38, 3-9. https://doi.org/10.1016/j.ienj.2018.03.002

Xia, S., Yang, B., Chen, X., Petrini, M.A., Schory, S.A., Liu, Q., 2016. Application and effects of a disaster nursing simulation training for Chinese undergraduates. Journal of Nursing Education and Practice 6. https://doi.org/10.5430/jnep.v6n10p8

Yan, Y.E., Turale, S., Stone, T., Petrini, M., 2015. Disaster nursing skills, knowledge and attitudes required in earthquake relief: Implications for nursing education: Disaster nursing in earthquake relief. International Nursing Review 62, 351-359. https://doi.org/10.1111/inr.12175 